\title{
Evaluation of Oral Hygiene in Type 2 Diabetics with and without Diabetic Retinopathy - A Comparative Study Done at Yenepoya Hospital
}

\author{
Mallika S. Shetty ${ }^{1}$, Hasan Sarfaraz², Sanath Kumar Shetty³, Tushar Milind Wankhede ${ }^{4}$ \\ 1,2,3,4 Department of Prosthodontics, Crown and Bridge, \\ Yenepoya Dental College, Yenepoya University, Mangalore, Karnataka, India.
}

\section{ABSTRACT}

\section{BACKGROUND}

Diabetic retinopathy (DR) is a major microvascular complication of diabetes. It has a significant impact on the world's health systems. Due to a rapid increase in disease burden globally, there arises the need for newer methods of early detection of DR to prevent various complications including total blindness. The association between periodontal problems and diabetes has been studied widely and a positive correlation has been found. Literature search revealed that no studies have been done so far comparing the oral hygiene status among type 2 diabetics with and without retinopathy, thus the purpose of the study was to compare oral hygiene status among type 2 diabetics with and without progressing diabetic retinopathy and thus look for any association between existing oral hygiene status and severity of diabetic retinopathy.

\section{METHODS}

Study was conducted on type 2 diabetic patients with and without progressing diabetic retinopathy visiting the Department of Opthalmology at the University Medical College. A thorough evaluation of oral hygiene status of patients participating in the study was done using $\mathrm{OHI}$ - S and Gingival Index.

\section{RESULTS}

There was no statistically significant difference between the OHI - S and diabetic retinopathy, $P$ value $(0.522)$. The gingival index showed statistically significant relation with severity of diabetic retinopathy with $\mathrm{P}$ - value of 0.027 . The intergroup comparison of the association between the mean OHI - S and GI scores and severity of diabetic retinopathy was found to be statistically insignificant $\mathrm{P}<0.269$ and $\mathrm{P}<$ 0.125 .

\section{CONCLUSIONS}

There could be a plausible relationship between diabetic retinopathy and oral hygiene condition. Because of the regional variation in the oral hygiene condition further prospective studies on a large population are required to ascertain whether the existing oral hygiene status has a direct impact on the progression and severity of diabetic retinopathy.

\section{KEY WORDS}

Diabetic Retinopathy, Oral Hygiene, Periodontitis, Type 2 Diabetes Mellitus, Oral Hygiene Index Simplified, Gingival Index
Corresponding Author: Dr. Tushar M. Wankhede, Department of Prosthodontics, Crown and Bridge, Yenepoya Dental College, Yenepoya University, University Road, Deralakatte, Mangalore - 575018,

Karnataka, India.

E-mail: tuushar18@gmail.com

DOI: $10.14260 /$ jemds/2021/509

How to Cite This Article:

Shetty MS, Sarfaraz H, Shetty SK et al. Evaluation of oral hygiene in type 2 diabetics with and without diabetic retinopathy - a comparative study done at Yenepoya hospital.J Evolution Med Dent Sci 2021;10(31):2490-2493, $10.14260 / \mathrm{jemds} / 2021 / 509$

Submission 24-03-2021, Peer Review 26-05-2021, Acceptance 03-06-2021, Published 02-08-2021.

Copyright (C) 2021 Tushar Milind Wankhede et al. This is an open access article distributed under Creative Commons Attribution License [Attribution 4.0 International (CC BY 4.0)] 


\section{BACKGROUND}

Peridontal diseases have been regarded as the sixth complication of diabetes. For ages patients suffering from diabetes have been experiencing severe periodontal breakdown. So, a positive co-relation does exist between periodontal problems and diabetes mellitus. Diabetes is a metabolic disorder that results from high blood glucose levels due to problem in insulin production and insulin action. Prolonged hyperglycaemia can lead to many complications, which can be classified into macrovascular (coronary artery disease, peripheral arterial disease, and stroke) and microvascular (nephropathy, neuropathy, and retinopathy). ${ }^{1}$ World health organization (WHO) estimated the prevalence of DM worldwide in adult population to be $4 \%$ in 1995 and has predicted to rise to $5.4 \%$ by $2025 . .^{2}$ The overall prevalence of DM in India is estimated to be $7.3 \%$ and the prevalence of prediabetes is $10.3 \%$ based on the WHO criteria; whereas it is $24.7 \%$ based on the American dental association ADA criteria. ${ }^{3}$ It is also beginning to appear much earlier in life, and chronic long term complications are becoming more common. ${ }^{4}$ A microvascular complication of chronic DM is diabetic retinopathy. It is found to be the most frequent cause of new cases of blindness among adults aged $20-74$ years. ${ }^{5}$ DR can be divided into two stages: non-proliferative diabetic retinopathy (NPDR) and proliferative diabetic retinopathy (PDR).

Most of the studies evaluating the relation between periodontitis and DR included small number of subjects and did not consider possible confounders. ${ }^{6,7}$ One study by Borgnakke et al. performed among 100 patients with type 2 diabetes found that the, probing pocket depth, and clinical attachment loss were significantly different between patients with and without diabetic retinopathy; however, after adjusting for confounders, these results failed to show significant effects. ${ }^{8}$ As diabetic retinopathy is the most common cause of blindness among the working population worldwide, evaluating the relationship between diabetic retinopathy and periodontal disease will provide important clinical information for persons with diabetes, ${ }^{9-11}$ and this information may help improve the socioeconomic burden caused by diabetes related complications in the future. Thus the purpose of the study was to compare oral hygiene status among type 2 diabetics with and without progressing diabetic retinopathy and thus look for any association between existing oral hygiene status and severity of diabetic retinopathy.

\section{METHODS}

Approval of the University Ethics Committee was taken prior to starting the study. Informed written consent was taken from the subjects before enrolling them for the study. The patients were explained about the details of the study, examination procedure, time and financial implications, potential risks and expected benefits of participating in the study. The hospital based, descriptive, cross sectional, observational study was conducted on 90 patients. Sample size was calculated using G - power software with the level of significance -
Power $1-$ beta $=80 \%$

Effect size $\mathrm{d}=0.3$

$P$ value $<0.05 \%$ was considered to be significant

The total sample size of 90 was further divided into 2 groups: With and without DR with 45 subjects each. The patients were selected based on the following inclusion criteria: Patients aged between 40 and 75 years, irrespective of gender and medically diagnosed with Type 2 Diabetes Mellitus. Type 2 diabetic patients were further categorized as Group I without Diabetic Retinopathy and Group II with Diabetic Retinopathy, NPDR or PDR, with or without clinically significant macular edema (CSME) visiting Dept. of Opthalmology at the Medical College.

Patients with history of systemic conditions like hypertension, cardiovascular diseases, malignancy, autoimmune diseases and receiving medical treatments that could influence the studied parameters (such as antibiotics, antiepileptic, or immunosuppressive drugs) were excluded from the study. The subjects underwent a routine clinical and laboratory evaluation, including information regarding blood glucose level and HbA1c, diabetes duration, and the type of diabetic treatment obtained from the medical records. Fundus examination was performed by a trained ophthalmologist.

Once the examination was done scores were tabulated and given for statistical analysis. The diabetic retinopathy was graded using the International Clinical Diabetic Retinopathy Disease Severity Scale, evaluation of oral hygiene status was done based on the Oral hygiene index simplified (By Greene and Vermillon) ${ }^{12}$ and Gingival index (By loe and Silness). The categorization of readings obtained were done in accordance to the range of values provided by the index. Accordingly they were categorized as good, fair and poor based on the plaque and calculus index. The gingival index was evaluated by taking into consideration six index teeth. The index teeth were: 16 maxillary right first molar, 12 - maxillary right lateral incisor, 24 - maxillary left first premolar, 36 - mandibular left first molar, 32 - mandibular left lateral incisor, 44 - mandibular right first premolar. The evaluation was based on score from 0 $-3.13$

\section{Study Duration}

4 months

- November 2020 to January 2021 (3 months): Collection of data.

- February 2021 (1 month): Analysis of data and preparation of dissertation.

- March 2021: Submission of the dissertation to the University.

\section{Statistical Analysis}

The data was analysed using statistical package for the social sciences (SPSS version 23). Frequency and percentage was used for categorical data. Independent sample T test was used to compare oral hygiene status among type 2 diabetes mellitus patients with and without retinopathy. Chi square test was used to find an association between existing oral hygiene status and severity of diabetic retinopathy. P value $<0.05$ was considered as statistically significant.

Alpha $=5 \%$ 


\section{Ethical Statement}

Yenepoya Ethics Committee 2 Yenepoya (Deemed to Be University) DCGI Registration No.: ECR / 1337 / Inst / KA / 2020 Protocol No: YEC2 / 501.

\section{RESULTS}

Table 1. shows the distribution of cases pertaining to gingival inflammation in patients with and without diabetic retinopathy. Majority of the cases in both the categories showed moderate gingival inflammation. $34.4 \%$ cases were having diabetic retinopathy and $28.9 \%$ cases were without diabetic retinopathy with a P-value of 0.125 which was considered statistically insignificant.

\begin{tabular}{|c|c|c|c|c|c|}
\hline \multirow{2}{*}{\multicolumn{2}{|c|}{\begin{tabular}{|} 
With and \\
Without \\
Diabetic \\
Retinopathy \\
(DR)
\end{tabular}}} & \multicolumn{3}{|c|}{ Gingival Index - Loe \& Silness } & \multirow[t]{2}{*}{$P$ - Value } \\
\hline & & \multicolumn{3}{|c|}{ InflammationInflammationInflammatio } & \\
\hline \multirow[t]{2}{*}{$\begin{array}{c}\text { Absent } \\
\text { DR }\end{array}$} & Count & 7 & 31 & 7 & \multirow{4}{*}{0.125} \\
\hline & $\%$ of Total & $7.8 \%$ & $34.4 \%$ & $7.8 \%$ & \\
\hline \multirow{2}{*}{$\begin{array}{l}\text { Present } \\
\text { DR }\end{array}$} & Count & 4 & 26 & 15 & \\
\hline & $\%$ of Total & $4.4 \%$ & $28.9 \%$ & $16.7 \%$ & \\
\hline \multicolumn{6}{|c|}{$\begin{array}{l}\text { Table 1. Distribution Showing Gingival Index for } \\
\text { Patients with and without Diabetic Retinopathy (DR) }\end{array}$} \\
\hline
\end{tabular}

Table 2. shows the distribution of the condition of oral hygiene in patients with and without diabetic retinopathy; Majority of cases depicted fair oral hygiene in both the groups with $30 \%$ cases having diabetic retinopathy and $25.6 \%$ cases without diabetic retinopathy with a P-value of 0.269 which was considered statistically insignificant.

\begin{tabular}{|c|c|c|c|c|c|}
\hline \multirow{2}{*}{\multicolumn{2}{|c|}{$\begin{array}{l}\text { With and without Diabetic } \\
\text { Retinopathy(DR) }\end{array}$}} & \multicolumn{3}{|c|}{$\begin{array}{l}\text { Oral Hygiene Index - } \\
\text { Simplified (OHI - S) }\end{array}$} & \multirow[t]{2}{*}{ P - Value } \\
\hline & & Good & Fair & Poor & \\
\hline Absent DR & Count & 8 & 23 & 14 & \multirow{4}{*}{0.269} \\
\hline \multirow{3}{*}{ Present DR } & $\%$ of Total & $8.9 \%$ & $25.6 \%$ & $15.6 \%$ & \\
\hline & Count & 7 & 27 & 15 & \\
\hline & $\%$ of Total & $3.3 \%$ & $30 \%$ & $16.7 \%$ & \\
\hline
\end{tabular}

Table 3. shows the comparison of oral hygiene status in type 2 diabetics with and without diabetic retinopathy. There is no significant difference with a P-value of 0.522 for OHI - S index. But a statistically significant relation was established between gingival index when compared with both the groups $\mathrm{P}<0.027$

\begin{tabular}{|c|c|c|c|c|c|}
\hline $\begin{array}{l}\text { With and } \\
\text { without } \\
\text { Diabetic } \\
\text { Retinopathy }\end{array}$ & Indices & $\begin{array}{c}\mathbf{P} \\
\text { Value }\end{array}$ & $\begin{array}{c}95 \% \\
\text { Confidence } \\
\text { Interval }\end{array}$ & Mean & $\begin{array}{c}\text { Std. } \\
\text { Devaiation }\end{array}$ \\
\hline & $\begin{array}{l}\text { Oral Hygiene Index - } \\
\text { Simplified (OHI - S) }\end{array}$ & 0.522 & $\begin{array}{c}-0.401 \text { to } \\
0.13\end{array}$ & 2.2 & 0.635 \\
\hline & $\begin{array}{l}\text { Gingival index - Loe } \\
\text { and Silness }\end{array}$ & 0.027 & $\begin{array}{c}-0.40 \text { to }- \\
0.014\end{array}$ & 2.1 & 0.593 \\
\hline \multicolumn{6}{|c|}{ Table 3. Comparison of Oral Hygiene Status among } \\
\hline
\end{tabular}

Table 4. shows the intergroup comparison of the association between the mean $\mathrm{OHI}$ - S and GI scores and severity of diabetic retinopathy and it was found to be statistically insignificant $\mathrm{P}<0.269$ and $\mathrm{P}<0.125$.

\begin{tabular}{|c|c|c|c|}
\hline $\begin{array}{c}\text { With and without } \\
\text { Diabetic } \\
\text { Retinopathy }\end{array}$ & Dental Indices & $\begin{array}{c}\text { Chi } \\
\text { Square }\end{array}$ & P Value \\
\hline & $\begin{array}{c}\text { Oral Hygiene Index - } \\
\text { Simplified }\end{array}$ & 2.62 & 0.269 \\
\hline & $\begin{array}{c}\text { Gingival index - Loe and } \\
\text { Silness }\end{array}$ & 4.16 & 0.125 \\
\hline
\end{tabular}

Table 4. Association between Existing Oral Hygiene Status and Severity of Diabetic Retinopathy (DR)

\section{DISCUSSION}

For over a decade, there has been a concrete evidence on diabetes mellitus as an important risk factor for periodontitis, with increased levels of inflammatory markers acting as a common pathologic mechanism for both disease entities. ${ }^{14-18}$ A programmed mechanism of diabetic effect on the oral hygiene is that diabetes enhanced inflammation has a profound effect on the periodontal tissues thus leading to a compromised oral health. An increased risk of oral health issues and poor glycemic control is influenced by the different lesions and periodontal infections that alter the oral microflora. A poor metabolic state also affects the periodontal harmony thus leading to poor oral health.

There has been epidemiological proof suggestive of the frequency and severity of periodontal impairment in type 2 diabetic individuals. Eldarrat described a significant association $(\mathrm{P}<0.05)$ between glycemic control and oral infections and between the duration of diabetes and denture problems. ${ }^{19}$ A metabolic control to some extent can be obtained through periodontal therapy. ${ }^{20}$

In the present study, it was found that despite fair to poor oral hygiene in both the groups, the diabetics showed a significantly higher gingival bleeding, based on gentle probing of the gingival sulcus which may be suggestive of greater periodontal vulnerability. These observations are similar with most studies that consider diabetics to show inflammation and breakdown of supporting structures in response to the accumulation of bacterial plaque. ${ }^{21}$ The present study also revealed more periodontal attachment loss and more pathological periodontal pockets in the diabetic patients than in the control group which is in concordance with the observations of Oliver and Tervonen.

There was no significant relationship between existing oral condition and severity of diabetic retinopathy after evaluating both gingival index and oral hygiene index simplified. However, compared to the periodontitis grade the OHI - S and gingival index may be a more objective, easy, and quick screening method to assess the overall oral health. Moreover, using these two indices can have additional advantages over using the periodontitis grade, as it reflects both periodontal health status and dental function.

Even though our study failed to establish a relationship between oral hygiene status and diabetic retinopathy, we feel that the dentists should acknowledge the risk of diabetic retinopathy when examining patients with diabetes with missing teeth and, if indicated, refer them to an ophthalmologist for fundus examination as these 2 entities may have close association with one another, thus reflecting chronic microvascular damage among diabetes. 


\section{CONCLUSIONS}

Within the limitations of this cross-sectional study it was found that the sample size taken up for the study was limited and a concrete cause and effective relationship between severity of diabetic retinopathy and severity of existing oral health condition could not be established. But a general observation that most of the diabetic patients were found to have slight awareness of their increased risk for oral diseases even though the indices showed most of the patients falling in fair to poor criteria.

\section{Limitations}

The present study has two limitations which needs to be addressed. First, it is a hospital based cross-sectional study with limited sample size so it is not specific whether the existing oral health condition directly affects the progression of diabetic retinopathy. Further prospective studies with a large population are necessary to confirm the association between progression and severity of diabetic retinopathy and existing oral hygiene status. Second, instead of the periodontitis grade, the $\mathrm{OHI}-\mathrm{S}$ and Gingival index are used as parameters for the oral health state.

Data sharing statement provided by the authors is available with the full text of this article at jemds.com.

Financial or other competing interests: None.

Disclosure forms provided by the authors are available with the full text of this article at jemds.com.

The authors express their gratitude to Dr. Sheetal (Asso. Prof. Dept of Ophthalmology) and Dr. Madhuri U (Post Graduate student, Dept. of Opthalmology) for all their support during the conduct of the study.

\section{REFERENCES}

[1] Al-Shammari KF, Al-Ansari JM, Moussa NM, et al. Association of periodontal disease severity with diabetes duration and diabetic complications in patients with type 1 diabetes mellitus. J Int Acad Periodontol 2006;8(4):10914.

[2] King H, Aubert RE, Herman WH. Global burden of diabetes, 1995-2025: prevalence, numerical estimates and projections. Diabetes Care 1998;21(9):1414-31.

[3] Anjana RM, Deepa M, Pradeepa R, et al. Prevalence of diabetes and prediabetes in 15 States of India: Results from the ICMR-INDIAB population-based cross-sectional study. Lancet Diabetes Endocrinol 2017;5(8):585-96.

[4] Wilmot E, Idris I. Early onset type 2 diabetes: risk factors, clinical impact and management. Ther Adv Chronic Dis 2014;5(6):234-44.

[5] Aiello LP, Gardner TW, King GL, et al. Diabetic retinopathy. Diabetes Care 1998;21(1):143-56.
[6] Banthia R, Raje S, Banthia P, et al. Evaluation of the association between periodontal disease and diabetic retinopathy. Gen Dent 2014;62(6):e28-32.

[7] Amiri AA, Maboudi A, Bahar A, et al. Relationship between type 2 diabetic retinopathy and periodontal disease in Iranian adults. N Am J Med Sci 2014;6(3):139-44.

[8] Borgnakke WS, Anderson PF, Shannon C, et al. Is there a relationship between oral health and diabetic neuropathy? Curr Diab Rep 2015;15(11):93.

[9] Vesterinen M, Ruokonen H, Furuholm J, et al. Oral health in predialysis patients with emphasis on diabetic nephropathy. Clin Oral Invest 2011;15(1):99-104.

[10] Yoon KC, Mun GH, Kim SD, et al. Prevalence of eye diseases in South Korea: data from the Korea National Health and nutrition examination survey 2008-2009. Korean J Ophthalmol 2011;25(6):421-33.

[11] Saaddine JB, Honeycutt AA, Narayan KM, et al. Projection of diabetic retinopathy and other major eye diseases among people with diabetes mellitus: United States, 2005-2050. Arch Ophthalmol 2008;126(12):1740-7.

[12] Yau JW, Rogers SL, Kawasaki R, et al. Global prevalence and major risk factors of diabetic retinopathy. Diabetes Care 2012;35(3):556-64.

[13] Greene JG, Vermillion JR. The simplified oral hygiene index. J Am Dent Assoc 1964;68(1):7-13.

[14] Löe H. The gingival index, the plaque index and the retention index systems. J Periodontol 1967;38(6):S6106.

[15] Ide R, Hoshuyama T, Wilson D, et al. Periodontal disease and incident diabetes: a seven-year study. J Dent Res 2011;90(1):41-6.

[16] Janket SJ, Baird AE, Jones JA, et al. Number of teeth, Creactive protein, fibrinogen and cardiovascular mortality: a 15-year follow-up study in a finnish cohort. J Clin Periodontol 2014;41(2):131-40.

[17] Saremi A, Nelson RG, Tulloch-Reid M, et al. Periodontal disease and mortality in type 2 diabetes. Diabetes Care 2005;28(1):27-32.

[18] Borgnakke WS, Ylostalo PV, Taylor GW, et al. Effect of periodontal disease on diabetes mellitus: systematic review of epidemiologic observational evidence. Jf Periodontol 2013;84(4):S135-52.

[19] Chen L, Magliano DJ, Zimmet PZ. The worldwide epidemiology of type 2 diabetes mellitus--present and future perspectives. Nat Rev Endocrinol 2012;8(4):22836.

[20] Eldarrat AH. Awareness and attitude of diabetic patients about their increased risk for oral diseases. Oral Health Prev Dent 2011;9(3):235-41.

[21] Grossi SG, Skrepcinski FB, DeCaro T, et al. Treatment of periodontal disease in diabetics reduces glycated hemoglobin. J Periodontol 1997;68(8):713-9. 